\title{
OS
}

Revista Organizações \& Sociedade

\section{Relações raciais e histórias de vida: trabalhadores industriais} negros em foco

2020, 27(94), 532-555

(C) Autor(es) 2020

DOI 10.1590/1984-9270947

ISSN 1984-9230

Racial relations and life stories: focus on black industrial workers

www.revistaoes.ufba.br

NPGA, Escola de Administração

Universidade Federal da Bahia

Matheus Arcelo Fernandes Silva

Luiz Alex Silva Saraiva ${ }^{b}$

Recebido: 29/05/2018

Aprovado: 07/08/2019

a Fundação João Pinheiro, Belo Horizonte, MG, Brasil

- Universidade Federal de Minas Gerais, Belo Horizonte, MG, Brasil

\section{Resumo}

A construção das identidades negras no Brasil é marcada por uma série de lutas que influenciaram diretamente os avanços institucionais recentes em relação à temática, além de contribuírem para a desconstrução do mito da democracia racial. 0 objetivo deste artigo é compreender e analisar como se apresentam elementos relacionados às relações raciais nas histórias de vida de trabalhadores industriais negros. Para isso, é empreendido um debate sobre elementos que marcam a construção das identidades negras no Brasil, bem como sobre a ideia de democracia racial. A partir do método indutivo, os dados foram produzidos com base em histórias de vida, material trabalhado mediante a análise estruturalista do discurso, em especial no que diz respeito aos elementos sócio-históricos que permeiam os discursos. Os dados apresentam as relações raciais nas histórias de Leila e Clóvis, sujeitos da pesquisa, sendo a primeira marcada por uma posição política quanto à miscigenação, e o segundo por ter sido vítima de racismo. As principais conclusões sugerem que, mesmo com os avanços institucionais proporcionados pelos movimentos negros, conscientizar-se da sua negritude é o primeiro passo para que as pessoas negras possam ocupar, efetivamente, qualquer lugar que desejem na sociedade.

Palavras-chave: Relações Raciais; Trabalho Industrial; História de Vida; Análise de Discurso; Identidades Negras.

\section{Abstract}

The construction of black identities in Brazil is marked by several struggles that directly influence recent institutional advances in this subject and contribute to the deconstruction of the racial democracy myth. This paper analyzes how elements 
related to racial relations are presented in the life stories of black industrial workers. For such, we discuss elements constitutive of the construction of black identities in Brazil, as well as the idea of racial democracy. By using the inductive method, data collection based on life stories was performed and treated by structuralist discourse analysis, especially concerning social-historic elements present in their discourse. The main data present racial relations in Leila and Clovis' stories, our research subjects, hers being a story of a political position regarding miscegenation and his the story of a racism victim. The main conclusions suggest that even with institutional advances of the black movement in Brazil, consciousness about self-blackness is the first step for black people to effectively occupy any place they want in society.

Keywords: Racial Relations; Industrial Work; Life Histories; Discourse Analysis; Black Identities.

\section{Introdução}

Trazer à baila temáticas raciais implica assumirmos lugares de fala, localizações sociais que se inscrevem em um debate estrutural (Ribeiro, 2017). Coelho Junior (2011) destaca que uma pessoa branca pensa sua identidade a partir de outros lugares, seja nação, classe, gênero, mas nunca numa raça - um aspecto silenciado, de modo que muitas vezes é taxado de racista quem aponta diferenças raciais. Isso diz muito a respeito das especificidades das relações raciais no Brasil, uma vez que pessoas brancas vão experimentar o racismo a partir do lugar de quem se beneficia das opressões das pessoas negras, que experimentam o racismo a partir do lugar de quem é objeto de opressão (Ribeiro, 2017). Essa é uma posição fundamental, além de considerar que é importante escutar, uma vez que só negros podem, de fato, falar do racismo que vivenciam. Nesse sentido, o lugar de fala implica uma escuta que transcenda a pesquisa meramente burocrática, ao qualificar os que narram suas histórias como sujeitos que têm algo a dizer.

Consideramos fundamental essa compreensão na construção do nosso trabalho, apresentando também a importância de entender os elementos sócio-históricos que marcam a inserção dos negros na sociedade brasileira, bem como o cenário de desigualdades raciais nas mais diversas esferas da vida, como, por exemplo, no trabalho, no extermínio da juventude negra da periferia e na hipersexualização dos corpos negros. No âmbito deste artigo, o foco recai sobre trabalhadores negros na indústria, o que nos levou a perguntar "Como se apresentam elementos relacionados às relações raciais nas histórias de vida de trabalhadores industriais negros?". Para responder a essa questão, este trabalho busca compreender e analisar como se apresentam elementos relacionados às relações raciais nas histórias de vida de trabalhadores industriais negros, o que 
será feito pela compreensão de elementos que marcam a construção das identidades negras, em especial a partir de aspectos morais, intelectuais e estéticos, bem como pela apreensão, a partir das histórias de vida de nossos sujeitos de pesquisa, de elementos relacionados às relações raciais em suas trajetórias.

Feitas essas considerações, será apresentada uma seção acerca da construção das identidades negras, seguida da metodologia. Em seguida, serão apresentadas duas seções que marcam elementos das relações raciais nas histórias de vida dos dois sujeitos deste trabalho. Por fim, serão feitas as considerações finais, tratando do debate dos elementos apontados por Leila e Clóvis, de forma conjunta.

\section{A construção das identidades negras}

A gente nasce preta, mulata, parda, marrom, roxinha, entre outras, mas tornar-se negra é uma conquista.

Lélia Gonzalez

Ao tratarmos da discussão das identidades negras, compreendemos a força política dessa construção, considerando, assim como Munanga (2015), que o trabalho do racismo é relegá-la a um segundo plano, convertendo-a em algo diferente, sendo a cena racial um espaço de estigmatização sistemática. Nesse sentido, a valorização da raça ou de uma comunidade racial visa estabelecer um vínculo a partir do qual será possível se erguer contra um cenário de subjugação: a invocação da raça nasce, portanto, de um sentimento de perda. Essa articulação, abarcada pela fala precedente de Leila González, se torna ainda mais importante se pensarmos no contexto brasileiro de discussão do racismo. No Brasil ainda há influência do mito da democracia racial, um ideário que se fortaleceu, em especial a partir de Gilberto Freyre, na década de 1930, segundo o qual existe uma convivência harmônica das raças no país, em especial quando comparado com outros países, como os Estados Unidos e a África do Sul, que nesse mesmo período possuíam sistemas de segregação racial legais (Guimarães, 2001; Telles, 2003). Munanga (1996) aponta que esse ideário dificultou inclusive a tomada de consciência por parte dos que sofriam com o racismo.

Os avanços institucionais obtidos nas relações raciais ganham ainda mais importância ao evidenciarem o debate das desigualdades em um contexto permeado pelo discurso da igualdade racial. Para além dos ganhos materiais, as conquistas contribuem para o debate, apontando para a existência do racismo, "uma crença na existência das raças naturalmente hierarquizadas pela relação intrínseca entre o físico e o moral, o intelecto e o cultural" (Munanga, 2000, p. 24) - uma construção social a partir de diversos elementos sócio-históricos. 
Gomes (2011) compreende as políticas de ações afirmativas como a confluência de saberes identitários, políticos e estéticos (corpóreos), conforme esquematizado no Quadro 1.

Quadro 1 - Saberes políticos, identitários e estéticos

\begin{tabular}{|l|l|}
\hline Saberes & $\begin{array}{l}\text { Nunca as universidades e órgãos governamentais debateram } \\
\text { tanto sobre o tema. As universidades passam a ter que lidar } \\
\text { com a chegada de sujeitos sociais concretos, que trazem } \\
\text { nolíticos } \\
\text { acadêmico, além de novas trajetórias de vida, diferentes } \\
\text { daquelas naturalizadas em nossa sociedade. }\end{array}$ \\
\hline $\begin{array}{l}\text { Saberes } \\
\text { Identitários }\end{array}$ & $\begin{array}{l}\text { Coloca novamente no centro do debate a discussão acerca da } \\
\text { "raça" e da construção de uma identidade negra, bem como da } \\
\text { questão racial, e essa identificação enquanto negro passa a tomar a } \\
\text { pauta de diversos lugares, com todas as contradições que acarreta. }\end{array}$ \\
\hline $\begin{array}{l}\text { Saberes } \\
\text { estéticos } \\
\text { (corpóreos) }\end{array}$ & $\begin{array}{l}\text { Ações afirmativas reeducam os negros e as negras em sua relação } \\
\text { com o corpo. Ao buscar compreender o processo que leva a essa } \\
\text { questão, há um reposicionamento em relação ao corpo negro, no } \\
\text { sentido da valorização de traços negros. Ou seja, uma reafirmação } \\
\text { de uma identidade muitas vezes negada pelo racismo. }\end{array}$ \\
\hline
\end{tabular}

Fonte: Gomes (2011).

Tais saberes contribuem para a formação das identidades negras a partir da desconstrução do ideário da democracia racial. Os saberes políticos se articulam, uma vez que a questão racial nunca foi tão amplamente debatida, o que permite a reflexão sobre o tema, assim como a chegada de pessoas negras às universidades faz com que a academia tenha que se abrir a trajetórias de vida diferentes e a distintas formas de se ver o conhecimento. Nesse sentido, a primeira crise epistemológica provocada pelas cotas é questionar a neutralidade racial do campo teórico, levando também a uma inevitabilidade de posicionamentos (Carvalho, 2006). A partir desse maior debate em torno da questão racial é possível construir saberes identitários e estéticos que contribuam para a formação das pessoas negras, questão que remete à autoaceitação e, com isso, a maiores possibilidades de articulação e luta contra o racismo.

Quando falamos de um cenário de desconstrução do mito da democracia racial, afirmamos que as pessoas negras são sujeitos de suas próprias histórias, desvelando as relações de privilégio da branquitude. Este conceito marca o lugar de privilégios a partir do qual falam e escutam as pessoas brancas no Brasil, experimentando o racismo do lugar de quem se beneficia com as opressões das pessoas negras (Ribeiro, 2017).

Passa por essa questão a construção das identidades negras, condicionadas por diversos fatores mediados pelos indivíduos, modificando e sendo modificados 
por eles. Souza (1983, p. 77) aponta a questão do "tornar-se negro", que não é uma construção a priori, sendo sobretudo política a construção da identidade negra. Falamos aqui de confrontar uma norma social construída: a superioridade branca, apontando que "o objetivo principal ao confrontarmos a norma não é meramente falar de identidades, mas desvelar o uso que as instituições fazem para oprimir ou privilegiar" (Ribeiro, 2017, p. 31).

Gomes (2017) destaca que qualquer processo identitário constitui uma dinâmica conflitiva, uma vez que pressupõe interação. Para os racistas, a cor preta é tida como uma essência que tinge negativamente aspectos morais, intelectuais e estéticos, justificando o padrão branco como superior. Além disso, a autora destaca que, no Brasil, o racismo que incide sobre os negros se dá não apenas em decorrência de um pertencimento étnico, mas pela conjugação desse pertencimento com a presença de sinais diacríticos inscritos no corpo, rejeitada pelo ideal de branqueamento e tratada de maneira eufemística pelo mito da democracia racial. Nesse sentido, os sinais diacríticos são compreendidos como um conjunto de elementos e características a partir das quais determinado grupo se identifica e se diferencia. É nesse contexto que Gomes (2017) apresenta o corpo como um elemento que se destaca nessa dinâmica de resistência sociocultural, mas também se apresenta como opressão e negação. Assim como a ideia da democracia racial, o cabelo e o penteado também podem ser utilizados para camuflar o pertencimento: "no caso dos negros, o cabelo é visto como um sinal diacrítico que imprime a marca da negritude no corpo" (Gomes, 2017 , p. 194). Tratar o cabelo do negro como "ruim" é expressão do racismo e da desigualdade racial que vive o sujeito. Alterações no cabelo, para uma pessoa negra, significam mais do que vaidade ou tratamento estético, são questões de identidade: "o cabelo como ícone identitário se destaca nesse processo de tensão, desde a recriação de penteados africanos, passando por uma estilização própria do negro no Novo Mundo, até os impactos do branqueamento" (Gomes, 2017, p. 112).

Gomes (2017) também discute a questão da identidade negra e aponta que, para que se altere a autoimagem desfavorável dos negros e sua imagem social, é preciso superar ações individuais, uma vez que, desde a escravidão, o homem e a mulher negra carregam o estigma da inferioridade de seus traços estéticos $A$ autora ainda aponta que, no contexto da África pré-colonial, o cabelo era visto como símbolo de status, realeza e poder, mas, a partir da escravidão, se torna símbolo de inferioridade. Entre as muitas formas de violência impostas aos escravizados, estava a raspagem do cabelo. Como o cabelo era considerado uma marca identitária para muitas etnias africanas, sua raspagem era uma forma de mutilação.

Além do cabelo, outras questões também marcam a formação das identidades negras, representadas por aspectos morais, intelectuais e estéticos (Gomes, 2017), representando também a complexa forma como operam as relações raciais no Brasil. 
Nesse sentido, a forma como as relações raciais foram se construindo hierarquizaram as raças e naturalizaram as desigualdades. Rejeitamos, portanto, a existência de um cenário de democracia racial no Brasil, considerando as relações raciais um elemento fundamental para refletirmos as assimetrias persistentes no país. No que se refere ao mundo do trabalho, por exemplo, a despeito dos avanços institucionais e dos debates que têm emergido em torno da questão racial e das desigualdades que se apresentam aos negros, o lugar do trabalho ainda é considerado, em grande medida, meritocrático, como se as relações raciais não importassem e não operassem de modo a estabelecer e manter "posições". "É dizer que o critério racial jamais foi relevante para definir as chances de qualquer pessoa no Brasil" (Bernardino, 2002, p. 249). Compreende-se meritocracia com base em Barbosa (2014), que sustenta que se trata de uma dinâmica assentada sobre critérios de seleção conhecidos por todos os envolvidos, com exigência de tipos específicos de qualificação, a partir dos quais se acredita em um cenário de igualdade de oportunidades, sendo o esforço dos sujeitos o que define o seu sucesso.

As relações raciais no Brasil se tornam especialmente complexas devido à contradição vivenciada no país. Se, por um lado, a maior parte dos brasileiros repete acriticamente a "celebração da sua diversidade e a relação harmoniosa entre as raças", por outro, as práticas sociais desvelam a manutenção de hierarquias raciais. Sobre isso, é preciso ter em mente que o que se toma por sociedade brasileira foi construída sobre um processo deliberado de apagamento e violento silenciamento da população negra, a quem foi, na prática, negado o status de "povo brasileiro". 0 racismo, de fato, tem se tornado cada vez mais uma atitude indesejável e pouco aceita, porém formas menos evidentes e difundidas de discriminação se apresentam, sem desafiar a norma social (Lins, Lima-Nunes, \& Camino, 2014; Pereira, Torres, \& Almeida, 2003). O racismo não opera apenas como um "desvio de personalidade" de determinado indivíduo em relação ao outro, mas se constitui no bojo das relações sociais, demarcando lugares e gerando desigualdades. Nesse sentido, "ser negro" é visto historicamente como um fenômeno negativado. Essas percepções são levadas ao âmbito do trabalho, muitas vezes a partir de representações dos negros como predispostos a exercer determinadas funções. No mercado de trabalho, as segregações são claras, porém nunca justificadas a partir das relações raciais, sobretudo nos setores de ponta, como indica Sansone (2004). Outro aspecto fundamental nesse debate é como o lugar que as pessoas ocupam pode influenciar a definição que fazem de si enquanto brancas ou negras, remetendo à estrutura de poder que se construiu nas relações raciais brasileiras. Para trazermos essa discussão, tomamos o estudo realizado por Sansone (1996), que demonstrou essa variabilidade de definições raciais de acordo com a idade, o tempo, os laços afetivos, a renda e, principalmente, o lugar, compreendido pelo autor como "áreas duras", "áreas moles" e "espaços negros". A posição ocupada pela pessoa, que se relaciona à sua renda e sua ocupação, influencia 
diretamente a classificação racial, com pessoas em "posições subalternas" tendendo a serem vistas como mais escuras. As áreas duras correspondem aos espaços nos quais os negros sofrem mais discriminação por serem espaços hegemonicamente brancos, como o mercado de trabalho. Se olharmos essa categoria em conjunto com a relação entre classe social, notamos que o mercado de trabalho é uma área dura no sentido de que os negros pouco avançam a posições de maior nível remuneratório e status social, enquanto as outras ocupações e o mercado informal seguem sendo áreas moles para eles. As áreas moles apresentadas por Sansone (1996) são as que possuem mais negros, não sendo, por isso, observada uma situação de competição por status e poder. São, em especial, ligadas ao lazer, nas quais ser negro não se torna um obstáculo em comparação às áreas duras. Já os espaços negros são aqueles nos quais a cultura negra se torna base das atividades desenvolvidas, como a capoeira e grupos carnavalescos. Gonzalez (1984) também destaca essa questão ao apontar que as condições de existência material da comunidade negra remetem a condicionamentos psicológicos que precisam ser atacados e desmascarados. Como exemplo, cita as condições de moradia de negros e brancos, além da questão do policiamento, que para os brancos significa proteção, enquanto que para os negros repressão.

A partir das questões apresentadas por Sansone (1996) e Guimarães (2016) e do caso dos shopping centers, apresentado por Nascimento, Oliveira, Teixeira e Carrieri (2015), percebemos as especificidades e a complexidade da definição racial no Brasil, tornando-se difícil sua análise a partir de um ponto fixo. Essa complexidade, somada ao ideário da democracia racial, que também estrutura em certa medida essas questões, é encarada como uma atitude desfavorável à luta antirracista, por parte de alguns movimentos negros, pois acaba por desarticular esse movimento, gerando perda de força política (Rosa, 2014; Sansone, 1996).

Esse "lugar" do qual tratamos e a partir do qual as histórias de vida serão narradas, é importante que se diga, abrange muitos lugares. Ao abordarmos aspectos sensíveis ao debate das relações raciais no Brasil, diversas questões surgem em nossas discussões cotidianas, como a das cotas raciais em universidades, lembrada por Carneiro (2011), combatida por alguns veículos de comunicação, que, no largo espectro de tonalidades da cor da pele, veem mais uma oportunidade para deslegitimar fenotipicamente o critério racial que orienta essa política. Quando tratamos dos brancos, por outro lado, é valorizada a diversidade da branquitude, a partir da sua individualidade e complexidade. A branquitude é, assim, diversa e policromática, o que não impede a maioria das pessoas de se verem como brancas, questão que nos remete ao discurso da raça branca tida como neutra e universal. Seguindo essa lógica, Carneiro (2011) destaca que são instituídas divisões raciais dentro das famílias negras, havendo para a autora um aceno de "traição à negritude" que se apresenta aos mais claros. Afinal, o embranquecimento passa a ser visto como algo positivo. A autora também destaca que essa base multidimensional da percepção da 
condição racial sugere a possibilidade de um indivíduo, que se considerava negro e vivenciou um cenário de ascensão social, poder se identificar como branco ou pardo posteriormente. Todos esses elementos são vividos pelas pessoas negras em suas vidas, marcando a construção de suas identidades enquanto negros, conforme veremos adiante, nas narrativas de Leila e Clóvis, nossos sujeitos de pesquisa.

\section{Metodologia}

Partindo do método indutivo, este artigo foi estruturado a partir de uma pesquisa qualitativa baseada em histórias de vida de dois trabalhadores industriais: Leila e Clóvis, nomes fictícios como todos os demais que aparecem nos relatos, com o intuito de preservar a identidade dessas pessoas que se dispuseram a se abrir e contar-nos suas vidas. Leila, de 48 anos, se autodeclara negra, é mãe de dois filhos e trabalha atualmente com atividades sindicais, tendo experiência no ramo metalúrgico. Clóvis, de 54 anos, também se autodeclara negro, tem dois filhos e teve larga experiência no ramo da metalurgia.

Utilizamos a corrente de história de vida, que se enquadra no campo da psicossociologia e foca, em certa medida, a relação entre o entrevistador e o entrevistado, uma alternativa adequada nos estudos organizacionais, como o trabalho realizado por Lopes (2015). Adotar essa perspectiva significa também descontruir a imagem reificada da organização, compreendendo que as organizações existem apenas por e para o homem (Saraiva 2009). Este ponto é fundamental, pois permite compreender que, além de sua função econômica, as organizações possuem uma dinâmica social da qual não se pode abrir mão enquanto objeto de análise, havendo inúmeras possibilidades de significação do ambiente da história da organização ao se ouvir o que os trabalhadores têm a dizer. Desse modo, as histórias de vida se apresentam como um caminho possível, pois permitem contar histórias muitas vezes silenciadas nas organizações (Barros \& Lopes, 2014). Considerando, assim, a história de vida em sua dimensão psicossociológica, Carvalho e Costa (2015) dizem: "Pode-se acessar o processo de constituição de uma sociedade quando se conhece o processo de constituição de uma História de Vida, pois ambos ocorrem simultaneamente, um atravessando e influenciando o outro e sendo modificado por esse outro" (p. 25).

Pinto, Carreteiro e Rodrigues (2015) apontam também para essa relação, considerando que o indivíduo não pode ser analisado sem considerar os inúmeros fatores que o atravessam: "a análise é sempre dialética, apreendendo o peso das condições sociais nas condutas humanas, e levando em conta a singularidade do trabalho psíquico" (p. 945). Essa perspectiva deve ser considerada, portanto, em sua complexidade, sendo uma possibilidade muito rica de apreender a relação dos sujeitos e o mundo o real que Ihes é apresentado, observando a maneira como 
negociam suas condições sociais, que os constroem, ao mesmo tempo, que por eles são construídas (Barros \& Lopes, 2014). Nesse sentido, são observados diversos fatores que atravessam os indivíduos, em especial aspectos morais, intelectuais e estéticos, que, em articulação, marcam a construção das identidades negras no Brasil (Gomes, 2017).

A opção pela utilização de histórias de vida traz consigo uma dimensão fundamental da escolha epistemológica deste estudo e da forma como a raça é considerada em seu aspecto sócio-histórico, sendo importante não apenas trazer à superfície a história dessas pessoas, como também compreender a relação dialética que exercem com o coletivo e o social. Queiroz (1988) coloca as histórias de vida em um quadro mais amplo da história oral, porém vê sua capacidade de aproximação entre o individual e o social como uma grande potencialidade. Assumimos que é impossível pensar em uma esfera histórica vivenciada pelo sujeito não relacionada dinamicamente com o coletivo e a sociedade em que ele se insere. Isso significa que os sujeitos e suas histórias são produtos de um momento histórico de sociedade e de uma coletividade, e simultaneamente tecem essa história (Gouvêa, López Cabana, \& Ichikawa, 2018).

Fundamental também para este estudo é a compreensão do papel central do sujeito que se conta, uma vez que a vivência e interação com a questão racial podem ser apreendidas apenas pelos que participam delas em seu interior. Essas pessoas podem oferecer elementos que muitas vezes escapam à análise fria dos dados, que remontam às desigualdades ou mesmo à análise sócio-histórica, fornecendo aspectos sociais dessa exclusão, mas não apontam como são vividos e mediados pelos indivíduos. Nesse sentido, a perspectiva das histórias de vida representa, nas palavras de Ferrarotti (1990), uma "história não historicista", o que significa dizer que se distanciam da historiografia oficial, uma vez que vão além da simples sucessão de fatos cronológicos, que remetem a uma noção ossificada da realidade social. Também se distanciam das histórias contadas pelos vencedores, das histórias das elites (Barros \& Lopes, 2014).

Para contribuir com o estudo dessas histórias de vida, utilizamos a análise estruturalista do discurso, que considera também aspectos sociais de produção do discurso, sendo a palavra, conforme aponta Bakhtin (2006), o "produto da interação entre o locutor e o ouvinte" (p. 99). Como o discurso não é de forma alguma neutro, é necessário superar a simples categorização dos dados, identificando e analisando os discursos enunciados explicita ou implicitamente, ou mesmo silenciados (Fiorin, 2003). Ao tratar das histórias de vida, Carvalho e Costa (2015) destacam que, "a fim de compreender a relação que o indivíduo possui com sua história, é imprescindível que se analise o sistema social ao [sic] qual integra, o tempo em que se encontra e o espaço que ocupa, condicionando-o como ser histórico-social" (p. 28). Seguindo essa linha, para a operacionalização dessa análise, estudamos estratégias discursivas de persuasão ideológica, como a seleção lexical, temas e figuras, interdiscursividade, sistematizadas por 
Saraiva (2009), usadas em conjunto ou separadamente, de acordo com o enunciado. A seguir, apresentamos aspectos relacionados às relações raciais nas histórias de vida de Clóvis e Leila.

\section{“Pardo? Que cor é essa?”: as relações raciais na história de vida de Leila}

Ao conversar com Leila ao telefone, antes de conhecê-la pessoalmente, ela nos falou sobre sua autodeclaração enquanto negra, fator fundamental para a participação nessa pesquisa. Ao longo das narrativas, um elemento que nos chamou atenção foi a forma como se percebia enquanto negra, destacando que, embora sua pele fosse mais clara, havia outros elementos que a faziam se ver como negra, como a raça/cor de seu pai e o seu cabelo. Ao tratar da temática das relações raciais no Brasil, um tema recorrente é o alto índice de miscigenação da população. Com isso, a autodeclaração também se coloca como uma questão, levantando muitas vezes a pergunta sobre quem seria negro ou não no país. Como aponta o estudo de Sansone (1996), vários fatores contingenciais atuam sobre as relações raciais no Brasil e perceber como Leila vivencia algumas dessas questões é o objetivo desta seção.

A construção da identidade negra não é um processo simples, conforme Souza (1983): ser negro no Brasil é tornar-se negro. Gomes (2011) também desenvolve esse debate, ao destacar que estamos em uma zona de tensão, da qual emerge um padrão de beleza corporal real e outro ideal. Considera-se o padrão ideal branco; mas o real é negro e mestiço.

(1) A questão racial, igual eu falei, tem menos tempo, tem mais ou menos uns cinco anos que eu milito nessa área. Por causa disso mesmo, da conscientização dos próprios metalúrgicos, e depois da família, falei mais de não saber ter essa consciência, ué, nós somos negros, nós somos negras, não existe é . . . pardo e marronzinho, beginho, é negro ou branco porque que que tem que ter essa consciência. Se você não tiver essa consciência, você não enxerga o racismo, então é. . . . É um jeito de você lutar pela sua raça e pela diferença que foi lá atrás, né, a diferença que teve por causa da escravidão que até hoje a gente sente na pele, a gente e muitas vezes a mulher negra, ela sente muito mais. (Leila, 2018)

(2) Tô fazendo um curso sobre a questão racial, estudando a história da África que eu acho que é uma coisa que a escola não é, que já saiu uma PEC que não vai ser obrigatório mais contar a história da África, e isso a gente percebe que as pessoas não consegue ver o racismo estrutural que existe, tendeu? Eu nunca senti na pele a questão racial, mas eu não sou branca né, eu não sou branca, então estruturalmente com certeza 
vou sentir pela minha questão, a minha questão financeira, pela minha questão de gênero, por meu pai ser negro, né, é . . . essas coisas, tudo, então a condições que ele teve com certeza, se ele fosse da cor mais clara, ele não ia sofrer tanto, ele ficou desempregado muito tempo e ele era profissional, e é complicado. (Leila, 2018)

A conscientização é explicitada nos fragmentos 1 e 2, nos quais Leila traz um discurso de mobilização das pessoas negras que combate a ideologia do discurso da democracia racial, exaltando a miscigenação e defendendo a ideia de um colorismo associado a um paraíso racial (Rosa, 2014). Esse embate fica explícito a partir da seleção lexical "se você não tiver essa consciência, você não enxerga o racismo", que remete ao aspecto interdiscursivo da cordialidade das relações raciais no Brasil, rompida apenas a partir da assunção da negritude e da ameaça ao status quo. Também chama a atenção, assim como aponta Coelho Junior (2011) em seu estudo sobre executivos negros, a importância do debate que passou a ser empreendido no Brasil, em especial a partir da década de 1990, sobre o tema. A história de consciência de Leila, assim, é ao mesmo tempo produto do contexto e ativamente produzida por ela.

Gomes (2011) destaca as ações afirmativas como um desses avanços e propõe que elas contribuíram para três saberes em especial: estéticos, identitários e políticos. Esses elementos estão muito presentes nas falas de Leila ao tratar da questão racial. Nesse sentido, também é importante destacar o quanto é marcante no processo de formação educacional de crianças negras a falta de uma discussão sobre as relações raciais nas escolas. A não existência do ensino das relações raciais nas escolas marca um processo de silenciamento, calcado no ideário da democracia racial, que termina por impor às crianças um ideal branco (Gonçalves, 1987). Assim, crianças negras são impedidas de ter contato com a cultura negra e, inclusive, de construir novas relações com sua ancestralidade e desconstruir as narrativas da historiografia oficial em relação à África (Mbembe, 2001). Embora a Lei 10.639, de 9 de janeiro de 2003, estabeleça a obrigatoriedade do ensino da "História Geral da África e do Negro no Brasil", sua implementação efetiva ainda é incipiente.

Outro elemento que chama atenção na fala de Leila é a forma como ela aponta a historicidade dessa questão, citando a escravidão (1). De acordo com Gomes (2011), essa concepção histórica foi uma das características marcantes das especificidades dos movimentos negros no Brasil, em relação a outros movimentos sociais, em especial ao buscar romper com a narrativa tradicional e poder contar a história do povo negro a partir de suas próprias perspectivas.

Ainda tratando do trecho 1 , a seleção lexical "a gente" ao dizer que "sente na pele" demonstra como Leila se define enquanto negra, não se esquecendo da questão de gênero, ao apontar que a mulher negra "sente muito mais". Já no texto 2 , 
ela explicita que, apesar dessa percepção da existência do racismo, nunca sentiu "na pele" a questão racial, mas destaca que não é branca e estruturalmente vai sentir por sua "questão financeira", por sua "questão de gênero" e por seu pai ser negro, fator de discriminação associado ao fato de ele ter ficado desempregado por um longo período. Nesse ponto, retomando Sansone (1996), pessoas com renda ou classe social mais baixa tendem a ser vistas como "mais escuras", já as com renda ou classe social mais alta tendem a ser vistas como "mais claras". Como vimos ao longo da história de vida de Leila, ela deixa explícita sua origem humilde: esse fator também deve ser levado em consideração quando pensamos na forma como a questão racial é apresentada por ela. Além disso, Leila tem consciência dessa questão, como fica explícito no texto 3, quando ela destaca que uma pessoa, quando tem melhores condições financeiras, "dá até uma clareada".

(3) Não é cor dela que vai colocar ela mais feia ou mais bonita, e eu sinto muito isso que a pessoa, quando tem uma condições melhor, ela até dá uma clareada, né? Ela pode ser tiziuzinho, mas se ela tem uma condição financeira maior, "Ah, até que ele não é muito preto não, né!". Já escutei isso e falei "Gente, é negro, mesma coisa! Só que ele usa uma roupa mais escovadinha, um cabelo mais melhorzinho, tem condição de ir no barbeiro mais vezes, mas é negro, mesma coisa". Aí que a pessoa vai parar pra pensar, mas muitas vezes você fica como chato, você fica como chata, tendeu? (Leila, 2018)

A seleção lexical da fala "eu não sou branca" (2) reforça a reflexão que Leila faz sobre sua classificação racial, complementada pela fala presente no fragmento discursivo 4: "Pardo? Que cor é essa?". Tal discurso também está presente no texto 1 , no qual ela aponta que, para ela, essa cor não existe. Também chamam a atenção, no fragmento discursivo 4, elementos que Leila destaca como a "miscigenação", "descendência" e "cor da pele" e que marcam sua compreensão de que, a despeito de sua pele ser mais clara, ela possui outras características que se somam à sua situação, para que se declare negra.

(4) Eu gosto de falar que do mesmo jeito que a gente não nasce mulher a gente se torna mulher, a gente não tem a consciência que é mesmo negro. Sensibiliza depois porque uma coisa é você ter a pele negra, outra coisa é você ter uma descendência negra, igual quando você não tem. No Brasil é mais pela cor da pele do que da nossa miscigenação. Sendo que eu tenho a sensibilidade que, se meu pai é negro, eu sou negra também, mas isso foi construído, isso em lugar nenhum mostra, nem na faculdade eu acho, nem na, no, no ensino médio não se fala disso . . . tem que ir lá atrás, lá na África pra cá, sensibilizar, aí sim eu descobri que, descobri não, eu me 
declaro negra nos documentos tudo, nunca me senti à vontade de falar que eu era parda. Pardo? Que cor que é essa? (Leila, 2018)

Além de fazer essa reflexão sobre a sua condição enquanto negra, Leila também a levou para sua família, em especial seu pai, que se declarava pardo. Como exemplo do grande peso que ela vê na condição de negro, ela também conta que sua avó tinha a pele "bem escura" (5), mas não aceitava que era negra, o que remete ao implícito pressuposto de que o simples fato de uma pessoa ter a pele mais escura não significa que ela se conscientize da questão racial, inclusive das lutas cotidianas que essa questão envolve, como aponta Ribeiro (2017). Por isso Leila também enfatiza diversas vezes o aspecto da conscientização.

(5) Eu sensibilizei ele. . . . Meu pai falava que era pardo, eu, "ué, pai, minha vó era, como se diz, bem escura da pele e não aceitava que era negra". Podia falar que era índia, mas não pode falar que é negro, porque isso aí a gente percebe que é um peso muito grande. Agora virou a mídia colocando aí os negros, né, "ah, os negros na mídia". Mas aquilo ali é só a mídia. No dia a dia a gente vê, nó. (Leila, 2018)

Leila também destaca a maior atenção que a mídia vem dando às pessoas negras, mas desconstrói esse discurso de valorização a partir de sua experiência cotidiana. Nesse sentido, a seleção lexical "nó", uma expressão regional muito utilizada no estado de Minas Gerais, serve para enfatizar que no dia a dia o racismo atua fortemente. Carneiro (2011) destaca que uma das características do racismo é a maneira como mantém as pessoas negras presas a um estereótipo, enquanto aos brancos é reservado o privilégio de serem representados em sua diversidade. Como exemplo, a autora destaca a produção de peças publicitárias nas quais "basta enfiar um negro no meio de uma multidão de brancos em um comercial para assegurar suposto respeito à diversidade étnica e racial" (Carneiro, 2011, p. 664). Em sua narrativa, Leila demonstrou percepção da realidade das pessoas negras no Brasil, assim como de seu papel, nessa dinâmica. Como destaca Ribeiro (2017), o fato de pessoas negras não apontarem casos específicos de discriminação vividos com elas não significa que o racismo não influencie suas vidas. É possível perceber essa questão quando vemos os relatos de Leila, que sofreu assédio sexual duas vezes, como pode ser observado nos fragmentos discursivos 6 e 7 .

(6) Eu passei por isso e o que me prejudicou muito pra mim melhorar na empresa pra crescer foi o assédio sexual. Meu patrão cismou que eu tinha que sair com ele, aí eu não saí com ele, ele parou de me dar o aumento porque antigamente quem dava o aumento era o encarregado, era o 
encarregado. "Ah, esse mês ou esse bimestre, eu vou ganhar tanto por cento", diferente do que era negociado com o sindicato. Então comecei a perceber que depois disso eu não ganhei nem um aumento mais e ele sempre falava que eu tava na lista de mandar embora e ainda usava uma pejorativa que era a lista negra, a lista negra. Então aquilo ficava na minha cabeça, e eu tava num momento que o meu pai tava desempregado, minha mãe desempregada, minha mãe fazendo uns bicos de lavar roupa, faxina e foi uma época muito difícil, que era anos noventa. (Leila, 2018)

(7) De dia ele não me atentava não, de dia eu fazia minhas coisas, o menino deles atentava. . . . Eu arrumava a casa, eles jogava as coisa no chão pra me atentar, mas eu percebi também que era falta de carinho, aos poucos a gente vai percebendo. . . . Fiquei lá, falava pra minha mãe: "Oh mãe, o moço não deixa eu dormir. ele fica me rodeando" Tinha só, era na sala. . . . Eles colocaram uma caminha e colocou um lençol. Eu via ele passando assim, toda hora, eu via ele passando, eu via ele passando. . . . Aí teve um dia que ele cismou de me dar um colar. Eu não chegava perto dele de jeito nenhum, morria de medo dele. Mas ele cismou, "não . . . vou colocar ué, você tá com medo de mim?" Falou assim: "você não quer trabalhar aqui não? então eu vou falar com sua mãe que você não vai trabalhar aqui mais não" e eu falei: "Ai meu Deus, a mãe vai falar de novo que é culpa minha, que eu não aguento ninguém chegando perto de mim, que sou arisca demais" Aí deixei. . . . Deixei ele colocar o colar. Quando ele foi colocar o colar, o colar caiu, ele enfiou a mão, mas eu virei um bicho. (Leila, 2018)

Essa situação que afeta as mulheres de forma geral, contudo a questão da hipersexualização da mulher negra é ainda mais marcada. Nesse sentido, o conceito de interseccionalidade é fundamental para que se compreenda que não existe uma primazia entre as categorias, tais como gênero, raça e classe, mas relações múltiplas entre elas: "Raça é a maneira como a classe é vivida. Da mesma forma que gênero é a maneira como a classe é vivida" (Davis, 1997, p. 8). Nesse sentido, Gomes (2011) destaca que cada vez mais, ao observarmos a realidade brasileira e mundial, pode-se perceber que não é possível empreender uma luta contra o racismo, o sexismo, a homofobia, o neoliberalismo e a exclusão social de forma isolada.

\section{"A dor mais profunda que já vivi": vivenciando o racismo na história de vida de Clóvis}

Quando já atuava como dirigente sindical, Clóvis foi vítima de racismo, e essa foi uma questão que marcou sua vida e redefiniu a forma como ele passou a lidar com as questões raciais. Contudo, ao longo de sua infância, também houve momentos 
em que a questão do racismo se fez presente. Esta seção trata dessas experiências no que diz respeito às questões raciais. Para Clóvis, a questão racial era algo com que sempre conviveu; porém, muitas vezes o racismo se apresentava de formas mais sutis, como brincadeiras e piadas.

(8) Isso eu era criança, era mais jovem, mas naquele período você não tinha uma formação, você não tinha um conhecimento de que que era aquilo, a gente sabia que era uma forma de discriminar, mas você ficava assim "ah...". Você não tinha reação. Na minha infância, por exemplo, sempre você era rotulado de vários nomes né, é, macaco, é isso, é aquilo, aquelas brincadeiras sem, sem graça, né, e você ia superando porque às vezes assim, quando você tava no meio, a turma, cada um arrumava uma forma de, de gozação, de como diz o outro, de tirar um sarrozinho e, como você não tinha formação, num tinha uma, uma um entendimento maior da coisa, então você acabava deixando pra lá, "ah, deixa pra lá, é assim mesmo". (Clóvis, 2018)

O fragmento discursivo 8 retrata a percepção da questão racial que ele tinha em sua infância, porém, "deixava para lá", naturalizando a questão, por mais que destacasse saber "que era uma forma de discriminação", questão explicitamente enunciada. Ao demonstrar como ficava ao ouvir um insulto racial, a expressão "ah...", seguida por uma pausa e sem uma conclusão da fala, trata-se de um implícito subentedido de que essa era uma situação que incomodava, mas que, naquele momento, não gerava uma reflexão profunda sobre o assunto, fato explicitado pela figura da falta de formação destacada no início do texto 8. É possível notar, a partir de seleções lexicais como "macaco", que essas expressões eram proferidas em tom de "brincadeira", fazendo com que o racismo fosse expresso sob a forma de humor, fato que leva o enunciador da "brincadeira" a passar uma ideia de que "sua intenção é ser espirituoso e bem humorado, não advogar ou difundir alguma crença ou fato racista" (Sales Junior, 2006, p. 240). Nesse sentido, destaca-se o implícito segundo o qual quem não compreende a brincadeira ou a aceita se torna menos "desejável" socialmente, em especial num grupo de jovens que iniciam seus processos de sociabilidade. Irigaray, Saraiva e Carrieri (2010) apontam que piadas, ironias e anedotas naturalizam a violência, o que faz com esse relato exemplifique situações, muitas vezes vistas como sutis, que podem representar fortes elementos de discriminação e manutenção de estruturas de poder, como é o caso do racismo. A partir de questões frequentemente colocadas como formas de brincadeira e humor, Guimarães (1999, p. 67) chama a atenção para o que nomeou de "racismo à brasileira", um racismo velado e sutil.

Clóvis destaca que as "brincadeiras" feitas com ele não Ihe agradavam, mas, ao expressar que "cada um arrumava uma forma de, de gozação" (6), demonstra que também "entrava na brincadeira", reforçando a implícita naturalização das 
discriminações raciais vividas em sua infância. Isso sugere a forma como buscava superar essa questão nessa fase da vida: não por meio do embate, mas da aceitação de sua condição, uma vez que combatê-la significaria se isolar de seus amigos, sendo essa a forma de mediação encontrada por ele para lidar com a situação que se apresentava. Contudo, mesmo que Clóvis participasse das brincadeiras, isso não amenizava o seu sofrimento ao escutá-las. No trecho 9 , essa questão é explicitamente enunciada quando ele diz que ficava magoado e sem entender os ataques.

(9) Ficava magoado? Ficava. Você ficava sem entender, mas porque esses ataques todos, né? À medida que eu fui crescendo, fui adquirindo maturidade, a gente vai lendo, a gente vai estudando, agora eu só aprofundei mais depois mesmo que isso aconteceu com mais intensidade, uma coisa mais agressiva, mais violenta. (Clóvis, 2018)

Foi necessário, nesse sentido, um aprofundamento da consciência em torno da questão racial para que hoje Clóvis percebesse a profundidade do que ocorreu com ele ainda na infância (9). O racismo se manifestou ao longo da vida de Clóvis, inclusive no episódio em que se manifestou com mais intensidade, descrito no fragmento discursivo 10. Ele destaca que foi chamado de "criolo vagabundo", ao estar liderando uma paralisação na fábrica onde trabalhava, enquanto atuava como dirigente sindical, e que todos aderiram à greve em solidariedade ao que ocorreu com ele.

(10) Começa que eu tinha 14 anos de empresa pra tentar fazer uma paralisação é, cercearam nossa paralisação, nossa mobilização e intimidar os trabalhadores. . . . Intimidar os trabalhadores é, eu fui agredido racialmente, né, chamado de criolo vagabundo, que eu ia tomar um tiro etc. E aquilo foi a gota d'água pra gente poder consolidar uma paralisação interna e comuniquei com os trabalhadores os fato ocorrido e aí aquelas que pegaram serviço mais tarde aderiram toda a nossa paralisação, aí daquela hora em diante a fábrica inteira ficou parada. Pessoas do escritório, pessoas da mecânica, pessoas da, da, dos laboratórios de engenharia. . . . Então todos aderiram àquela greve em solidariedade a minha pessoa também. (Clóvis, 2018)

Esse episódio de discriminação racial sofrido por Clóvis marcou profundamente sua vida. Ele aponta:

(11) É a dor mais profunda que eu carrego na minha vida até hoje, é uma marca que ninguém tira ela. Quando eu fui interpelado por um chefe 
da segurança da empresa que me fez ameaças, né, me discriminou racialmente me chamando de criolo vagabundo". (Clóvis, 2018)

Como contraponto ao ataque proferido pelo chefe de segurança, Clóvis complementa destacando que "pra quem trabalhava 14 anos dentro da empresa, como é que eu era vagabundo e me ameaçou de dar um tiro em mim". Nesse sentido, ele desconstrói a ideia de que o ataque proferido era apenas de uma questão do trabalho ou meramente pessoal contra ele, uma vez que ele dedicou anos de sua vida à empresa. 0 pressuposto é que Clóvis não incomodava enquanto não tinha uma posição de destaque ao atuar no chão de fábrica, pois havia uma convivência "harmoniosa entre as raças", regulada a partir de "regras de cordialidade", que pautam o mito da democracia racial (Sales Junior, 2006). Muitos autores, como Silva (2012) e Bernardino (2002), também destacam um "silenciamento" em relação ao tema das relações raciais, devido ao discurso da democracia racial.

A discriminação sofrida por Clóvis ter ocorrido quando ocupava uma posição de destaque na empresa também remete ao argumento exposto por Sansone (1996), que trata o mercado de trabalho como uma "área dura", um espaço hegemonicamente branco. Assim, a própria empresa possui áreas duras e áreas moles, sendo o chão da fábrica uma área mole, na qual a presença de pessoas negras não representa grande risco à manutenção do status quo. Porém, quando tratamos de cargos de liderança, estamos falando de áreas duras. Assim, no momento que Clóvis passa a ter uma posição de maior destaque com sua atuação sindical, elementos relacionados às discriminações raciais passam a emergir e se tornam mais explícitos. Nesse momento, ele rompe com a dita convivência harmoniosa entre as raças e se passa a perceber, a partir de um exercício de reflexão, como diversas outras ações, muitas vezes "veladas", também representavam discriminação racial em seu dia a dia, marcando seus lugares e sua condição de negro.

(12) É muito traumático pras pessoas. . . . Porque às vezes elas não, as pessoas. . . . Quando você fala assim: "ah, no Brasil é, não tem discriminação racial"; "ah, mas as pessoas são muito sentimentais". . . . É só as pessoas que passam, é só as pessoas que passam pela situação que, que nós negros passamos é que sabem como que a dor é profunda, ela é um dor sem medida. Porque você não vê, você não consegue sentir é. . . . E quando você olha pro seu opressor, você olha com o olho dentro do olho dele e você consegue ver, você vê ele e vê e imponência a impunidade. Você vê a impunidade, aí é mais triste ainda e quando você vê um juiz, e quando você vê um juiz fazer um prejulgamento, fazer um prejulgamento aí é pior. (Clóvis, 2018) 
Clóvis aponta que o sentimento de dor causado pela discriminação racial pode ser compreendido apenas por quem vivenciou esse tipo de situação, destacando também o tema da justiça e o percurso semântico da impunidade presentes em seu caso de discriminação racial. Ele demonstra essa percepção ao não singularizar seu caso, tratando-o de forma genérica, em terceira pessoa, por mais que fique claro que ali também se inserem sua experiência e o caso de racismo que vivenciou. Ao tratar da impunidade no trecho 12, bem como ao retomar o tema no fragmento 10 , Clóvis coloca em questão o personagem do juiz enquanto figura "neutra", que deveria julgar e punir as discriminações. Isso é explícito na seleção lexical "pré-julgamento" (13), também permeado pelo racismo, ou por um ideário que trabalha com sua não existência, como o mito da democracia racial.

(13) Eu passando pra sentar antes de começar o proce. . . a audiência, ele disse assim: "daqui ele não leva nada", então assim, ele já fez um préjulgamento, né, até porque também esse juiz, ele é empresário, é, não sei qual que é o ramo de atividade dele, mas eu fiquei sabendo no histórico da empresa que ele é um juiz do ramo empresarial e ele achava que era um absurdo que no Brasil exista isso, isso não é verdade o que aconteceu. . . . Ele fez um pré-julgamento é eu perdi esse processo que ele foi arquivado, mas o, o discriminação racial, ele deu sequência, né, todas as testemunhas que ao meu favor é, foram, deram depoimento, colocaram como os fatos haviam ocorrido, né, mas é, a justiça com a promiscuidade dela com a falta de interesse é, foi empurrando com a barriga, eu digo assim, o processo até que, mas alguns dois anos atrás, chegou uma carta na minha casa, o oficial de justiça chegou lá, chamou na minha casa umas mais ou menos sete e pouca da manhã e me entregou uma carta dizendo que o processo foi arquivado, então assim é, primeiro frustração pelo que aconteceu, pelo que ocorreu, né, a segunda foi o prejulgamento da justiça que, que teve lado, foi parcialista e o terceiro foi o arquivamento. (Clóvis, 2018)

No fragmento discursivo 13, destacamos a seleção lexical "só quem passa por uma situação dessa sabe", a partir da qual é possível compreender o implícito subentendido de que apenas após passar por esse episódio que Clóvis pôde de fato sentir o que ser negro significava, que não é uma questão de vitimização, o que reforça os argumentos de Ribeiro (2017) sobre o que têm a dizer os oprimidos. Emerge o tema da empatia quando ele vivencia esse episódio.

(14) Isso é como a, é, ferir você no fundo da alma, só quem passa por uma situação dessa é que sabe qual que é a dor profunda que você sente, qual é o tamanho da ferida e da, da, e da cicatriz que fica. Pode sarar, as, a cicatriz fica e ela fica no interior que ninguém vê, ela fica no seu 
subconsciente, é só você que lembra, é só você que sabe que o filme que ele é, um filme que ele nunca sai de cartaz, ele fica na sua mente o tempo todo. Quando você vê uma discriminação com outra pessoa você volta lá no passado, eu volto lá em 2002, aí você fica com aquela ânsia de justiça. (Clóvis, 2018)

Essa empatia é explicitada pela seleção lexical "ânsia de justiça", expressão que alude à ação que moveu, sem o resultado esperado, no âmbito jurídico. Essa questão marca muito Clóvis, e marcaria qualquer pessoa que, violentada durante toda a vida sem sabê-lo, ao tomar consciência e usar da legislação para fazer valer a sua condição de cidadania, se vê abandonada pelo Estado.

\section{Considerações finais}

Compreender e analisar como se apresentam elementos relacionados às relações raciais nas histórias de vida de trabalhadores industriais negros foi o objetivo deste artigo. Os dados produzidos por meio das histórias de vida sugerem que a construção das identidades negras no Brasil não é, definitivamente, uma questão trivial. Segundo Souza (1983, p. 77), "ser negro não é uma condição dada a priori. É um vir a ser. É tornar-se negro". Nesse sentido, a autora aponta que nascer com a pele negra, ou com outras características físicas, como o cabelo ou o formato do nariz, não organiza, por si só a constituição de uma identidade negra no país. A possibilidade de construção dessa identidade é uma tarefa eminentemente política, que esbarra em inúmeras barreiras de valorização dos brancos, vistos como o padrão a ser alcançado (Souza, 1983). Enquanto isso não for objeto de atenção, corre-se o risco de os negros reproduzirem o racismo de que são vítimas.

Nesses processos que marcam o entender-se negro, Clóvis e Leila tiveram mediações distintas diante das questões que Ihes eram impostas. Um elemento comum a ser considerado quando tratamos dos dois enquanto trabalhadores industriais é a atuação de ambos enquanto dirigentes sindicais. Tal experiência representa uma singularidade na atuação dos sujeitos desta pesquisa, não pretendendo generalizar essa condição para todos os trabalhadores industriais. Mais ainda: é plausível supor que a aproximação com pautas de luta e de resistência os deixe em condições de refletir com maior propriedade sobre outros aspectos que os colocam na condição de resistir: como serem negros, pobres, trabalhadores etc.

Para Clóvis, essa questão se apresentou desde a infância, como forma de "brincadeira" pelo seu tom de pele mais escuro, sendo sua fala atual consciente sobre o racismo que sofreu ao longo do tempo. Esse tom de "brincadeira" muitas vezes presente ao se referir a pessoas negras remete a uma das características do racismo no 
Brasil, a pretensa cordialidade. Como o brasileiro tem preconceito de ter preconceito (Sales Junior, 2006), a prática explícita de discriminação racial é moralmente inaceitável, o que, todavia, não impede um recorrente racismo silencioso, velado, "bem humorado" e "espirituoso", que não tem a "intenção" de propagar ideários racistas, mas apenas "descontrair" - algo perverso -, como o sentido por Clóvis. Ele cresceu "se acostumando" ao racismo do qual era vítima porque este era travestido de "brincadeira". Assim, não tinha por que se ofender, embora não tivesse maturidade para lidar com a mágoa que tais brincadeiras provocavam nele.

O humor, ao naturalizar as agressões, disfarça as discriminações (Irigaray, Saraiva, \& Carrieri, 2010), pressionando o agredido a aceitar as "brincadeiras" e ser socialmente aceito ou reagir e correr o risco da exclusão social. É de se esperar que, no caso de Clóvis, isso tenha retardado a sua tomada de consciência sobre o racismo, o que impactou seu posicionamento político em relação ao tema. Assim como aponta Sales Junior (2006), em uma sociedade marcada por uma ideologia racista, como a brasileira, com lugares bem delimitados para brancos e negros, não é necessário mais que uma piada ou uma brincadeira para que uma pessoa negra se sinta desconfortável consigo mesma. No caso de Clóvis, esse estado de resignação só foi abalado por uma discriminação racial explícita, que o tirou do conforto da resignação cultivada ao longo de anos e o fez lutar por ter sofrido uma das maiores dores de sua vida, impune mesmo diante da gravidade do crime.

Leila, por sua vez, teve uma percepção distinta da sua identidade negra. Apesar de possuir um tom de pele mais claro, e talvez por isso não ter sofrido racismo explícito, ela se entende negra a partir de outras características, como a classe social, ancestralidade e cabelo. Recusando ironicamente o colorismo com que muitos negros são tratados "pardo, marronzinho, beginho" (fragmento 1), ela assume uma posição política necessária ao debate da miscigenação e da classificação racial brasileira, demonstrando que a micropolítica racial tem de beber, em primeiro lugar, na autopercepção - o que remete ao lugar social e não apenas às trajetórias individuais, assim como aponta Ribeiro (2017). Em outras palavras, somente quando os negros se reconhecem como tal, aprendendo a ser negros e tomando consciência de todas as assimetrias e falta de oportunidades a que estão sujeitos por conta de uma construção histórica que os diminui pelo seu tom de pele, é que podem, de fato, se articular em torno de demandas que tornem legítimas suas reivindicações. Aspectos como cotas, por exemplo, não são favor, mas reparação por quase 400 anos de uma construção aviltante das pessoas negras em nosso país. Além disso, é importante ressaltar que não devemos desresponsabilizar os sujeitos de poder (Ribeiro, 2017): essa conscientização deve partir de toda a sociedade, também a partir da compreensão dos elementos que marcam a branquitude e sua condição de privilégios, o que inclui problematizar o papel do Estado nessa dinâmica. 
Esse estudo tornou possível perceber que contribuíram para a construção das identidades negras de Clóvis e Leila as discussões empreendidas pelos movimentos negros, em especial a partir dos anos 1990, que permitiram um debate mais aberto sobre a questão racial, desvelando situações muitas vezes silenciadas. Ainda que se trate de uma mobilização social coletiva, deve se ter em mente que é singular a forma como cada pessoa lida com a construção da identidade negra, sendo muitas vezes uma construção contínua, acelerada por momentos críticos e amadurecida a partir de diversos conhecimentos adquiridos. Contudo, como vimos, desde a infância os conhecimentos sobre a questão racial são muitas vezes tratados como tabu e, por isso mesmo, silenciados, impedindo o acesso a essas questões, o que dificulta que muitas pessoas se vejam como negras e, assim, percebam-se vítimas do racismo em algumas situações. Como o processo é particular, não se trata apenas de uma questão de conscientização: mesmo cognitivamente adquiridos os conhecimentos necessários para que se considere negro, pode haver uma negação dessa condição devido à desvalorização social de características consideradas negras, como o formato do nariz ou o cabelo crespo. Gomes (2017) destaca que essa questão do cabelo é muito marcante na vida de mulheres negras, pois muitas consideram que isso as diminui porque as distancia da estética hegemônica (branca). Por isso é tão importante debater a representatividade, que auxilia na possibilidade de ocupação de qualquer função profissional e social por pessoas negras: o lugar da pessoa negra é onde ela quiser.

\section{Referências}

Bakhtin, M. (2006). Marxismo e filosofia da linguagem (8a ed.). São Paulo, SP: Hucitec.

Barbosa, L. (2014). Meritocracia e sociedade brasileira. Revista de Administração de Empresas, 54(1), 80-85. doi:10.1590/S0034-759020140108

Barros, V. A., \& Lopes, F. T. (2014). Considerações sobre a pesquisa em histórias de vida. In E. M. Souza (Org.), Metodologias e analíticas qualitativas em pesquisa organizacional: Uma abordagem teórico-conceitual (pp. 41-64). Vitória, ES: Edufes.

Bernardino, J. (2002). Ação afirmativa e a rediscussão do mito da democracia racial no Brasil. Estudos Afro-Asiáticos, 24(2), 247-273. doi:10.1590/ S0101-546X2002000200002

Carneiro, S. (2011). Racismo, sexismo e desigualdade no Brasil. São Paulo, SP: Selo Negro. 
Carvalho, J. C. B., \& Costa, L. F. (2015). História de vida: Aspectos teóricos da psicossociologia clínica. Revista Brasileira de Psicodrama, 23(2), 24-31. doi:10.15329/2318-0498.20150004

Carvalho, J. J. (2006). O confinamento racial do mundo acadêmico brasileiro. Revista USP, 68, 88-103. doi:10.11606/issn.2316-9036.v0i68p88-103

Coelho, P. J., Jr. (2011). Executivos negros: Racismo e diversidade no mundo empresarial: Uma abordagem sócio-antropológica (Tese de doutorado). Universidade de São Paulo, São Paulo, SP.

Davis, A (1997, 13 de dezembro). As mulheres negras na construção de uma nova utopia. Artigo apresentado na I Jornada Cultural Lélia Gonzales, São Luís, MA. Recuperado de https://bit.ly/338JSCz

Ferrarotti, F. (1990). Histoire et histoires de vie. Paris: Méridiens Klincksieck.

Fiorin, J. L. (2003). Linguagem e ideologia (7a ed.). São Paulo, SP: Ática.

Gomes, N. L. (2011). O movimento negro no Brasil: Ausências, emergências e a produção dos saberes. Política \& Sociedade, 10(18), 133-154. doi:10.5007/2175-7984.2011v10n18p133

Gomes, N. L. (2017). Sem perder a raiz: Corpo e cabelo como símbolos da identidade negra. Belo Horizonte, MG: Autêntica. doi:10.5007/21757984.2011v10n18p133

Gonçalves, L. A. O (1987). Reflexão sobre a particularidade cultural na educação das crianças negras. Cadernos de Pesquisa, 63, 27-29. Recuperado de https://bit.ly/2Q4RTTB

Gonzales, L. (1984). Racismo e sexismo na sociedade brasileira. Revista Ciências Sociais Hoje, 1984, 223-244. Recuperado de https://bit.ly/2IxsIVE

Gouvêa, J. B., López Cabana, R. P., \& Ichikawa, E. Y. (2018). As histórias e o cotidiano das organizações: Uma possibilidade de dar ouvidos àqueles que o discurso hegemônico cala. Farol: Revista de Estudos Organizacionais e Sociedade, 5(12), 297-347. doi:10.25113/farol.v5i12.3668

Guimarães, A. S. A. (2001). A questão racial na política brasileira (os últimos quinze anos).

Tempo Social: Revista de Sociologia da USP, 13(2), 121-142.

Guimarães, A. S. A. (2016). Formações nacionais de classe e raça. Tempo Social: Revista de Sociologia da USP, 28(2), 161-182. doi:10.11606/0103-2070. ts.2016.109752 
Irigaray, H. A. R., Saraiva, L. A. S., \& Carrieri, A. P. (2010). Humor e discriminação por orientação sexual no ambiente organizacional. Revista de Administração Contemporânea, 14(5), 890-906. Recuperado de https://bit.ly/2INND7f

Lei $n^{\circ}$ 10.639, de 9 de janeiro de 2003 (2003). Altera a Lei no 9.394, de 20 de dezembro de 1996, que estabelece as diretrizes e bases da educação nacional, para incluir no currículo oficial da Rede de Ensino a obrigatoriedade da temática "História e Cultura Afro-Brasileira", e dá outras providências. Recuperado de https://bit.ly/2TWeOga

Lins, S. L. B., Lima-Nunes, A., \& Camino, L. (2014). O papel dos valores sociais e variáveis psicossociais no preconceito racial brasileiro. Psicologia \& Sociedade, 26(1), 95-105. doi:10.1590/S0102-71822014000100011

Lopes, F. T. (2015). Entre o prazer e o sofrimento: Histórias de vida, droga e trabalho (Tese de doutorado). Universidade Federal de Minas Gerais, Belo Horizonte, MG.

Mbembe, A. (2001). As formas africanas de auto-inscrição. Estudos Afro-Asiáticos, 23(1), 171-209. doi:10.1590/S0101-546X2001000100007

Munanga, K. (1996). As facetas de um racismo silenciado. In L. Schwarcz, \& R. Queiroz (Orgs.), Raça e diversidade (pp. 213-229). São Paulo, SP: Edusp.

Munanga, K. (2000). Rediscutindo a mestiçagem no Brasil: Identidade nacional versus identidade negra. Belo Horizonte, MG: Autêntica.

Munanga, K. (2015). Negritude: usos e sentidos. Belo Horizonte: Autêntica.

Nascimento, M. C. R., Oliveira, J. S., Teixeira, J. C., \& Carrieri, A. P. (2015). Com que cor eu vou pro shopping que você me convidou? Revista de Administração Contemporânea, 19(n.esp. 3),245-268. doi:10.1590/1982-7849rac20151510

Pereira. C., Torres. A. R. R., \& Almeida, S. T. (2003). Um estudo do preconceito na perspectiva das representações sociais: Análise da influência de um discurso justificador da discriminação no preconceito racial. Psicologia: Reflexão e Crítica, 16(1), 95-107. doi:10.1590/S0102-79722003000100010

Pinto, B. O. S., Carreteiro, T. C. O. C., \& Rodriguez, L. S. (2015). Trabalhando no "entre": A história de vida laboral como método de pesquisa em psicossociologia. Farol: Revista de Estudos Organizacionais e Sociedade, 2(5), 941-985. doi:10.25113/farol.v2i5.3129

Queiroz, M. I. (1988). Relatos orais: Do indizível ao dizível. In O. R. M. V. Simson (Org.), Experimentos com história de vida (Itália/Brasil) (pp. 14-43). São Paulo, SP: R.T.

Ribeiro, D. (2017). O que é lugar de fala? Belo Horizonte, MG: Letramento. 
Rosa, A. R. (2014). Relações raciais e estudos organizacionais no Brasil. Revista de Administração Contemporânea, 18(3), 240-260. Recuperado de https://bit.ly/3aHULOI

Sales, R., Jr. (2006). Democracia racial: 0 não-dito racista. Tempo Social: Revista de Sociologia da USP, 18(2), 229-258. Recuperado de https://bit.ly/38Gx1Zx

Sansone, L. (1996). Nem somente preto ou negro: O sistema de classificação racial no Brasil que muda. Afro-Ásia, 18(2), 165-187. doi:10.9771/1981-1411aa. v0i18.20904

Sansone, L. (2004). Negritude sem etnicidade. Salvador, BA: Edufba.

Saraiva, L. A. S. (2009). Mercantilização da cultura e dinâmica simbólica local: A indústria cultural em Itabira, Minas Gerais (Tese de doutorado). Universidade Federal de Minas Gerais, Belo Horizonte, MG.

Silva, P. V. B. (2012). O silêncio como estratégia ideológica no discurso racista brasileiro. Currículo sem Fronteiras, 12(1), 110-129. Recuperado de https://bit.ly/335yyXI

Souza, N. S. (1983). Tornar-se negro. Rio de Janeiro, RJ: Graal.

Telles, E. (2003). Racismo à brasileira. Rio de Janeiro, RJ: Relume-Dumará.

\section{Sobre os Autores}

\section{Matheus Arcelo Fernandes Silva}

Mestre em administração pela Universidade Federal de Minas Gerais. Servidor público do Governo do Estado de Minas Gerais, lotado na Fundação João Pinheiro. E-mail: matheus.arcelo@gmail.com. ORCID: 0000-0001-8905-3739

\section{Luiz Alex Silva Saraiva}

Doutor em administração pela Universidade Federal de Minas Gerais (UFMG). Professor do Centro de Pós-Graduação e Pesquisas em Administração da Faculdade de Ciências Econômicas da UFMG. E-mail: saraiva@face.ufmg.br. ORCID: 0000-0001-5307-9750 